\title{
Identification of embryonic stem cell-derived midbrain dopaminergic neurons for engraftment
}

\author{
Yosif M. Ganat,, 1,2,3 Elizabeth L. Calder,1,2,3 Sonja Kriks, ${ }^{1,2}$ Jenny Nelander, ${ }^{4}$ Edmund Y. Tu,1,2,5 \\ Fan Jia, 6 Daniela Battista,1,7 Neil Harrison,6 Malin Parmar, ${ }^{4}$ Mark J. Tomishima, ${ }^{1,2,5}$ \\ Urs Rutishauser, ${ }^{1,7}$ and Lorenz Studer ${ }^{1,2,5,8}$

\begin{abstract}
${ }^{1}$ Center for Stem Cell Biology and 2Developmental Biology Program, Sloan-Kettering Institute for Cancer Research, New York, New York, USA. ${ }^{3}$ Program in Neuroscience, Weill Cornell Graduate School of Medical Sciences, New York, New York, USA. ${ }^{4}$ Department of Experimental Medical Science and Lund Stem Cell Center, Lund University, Lund, Sweden. ${ }^{5}$ SKI Stem Cell Research Facility, Sloan-Kettering Institute for Cancer Research, New York, New York, USA. ${ }^{6}$ Department of Anesthesiology, Columbia University, New York, New York, USA. ${ }^{7}$ Cell Biology Program and ${ }^{8}$ Department of Neurosurgery, Sloan-Kettering Institute for Cancer Research, New York, New York, USA.
\end{abstract}

\begin{abstract}
Embryonic stem cells (ESCs) represent a promising source of midbrain dopaminergic (DA) neurons for applications in Parkinson disease. However, ESC-based transplantation paradigms carry a risk of introducing inappropriate or tumorigenic cells. Cell purification before transplantation may alleviate these concerns and enable identification of the specific DA neuron stage most suitable for cell therapy. Here, we used 3 transgenic mouse ESC reporter lines to mark DA neurons at 3 stages of differentiation (early, middle, and late) following induction of differentiation using Hes5::GFP, Nurr1::GFP, and Pitx3::YFP transgenes, respectively. Transplantation of FACS-purified cells from each line resulted in DA neuron engraftment, with the mid-stage and latestage neuron grafts being composed almost exclusively of midbrain DA neurons. Mid-stage neuron cell grafts had the greatest amount of DA neuron survival and robustly induced recovery of motor deficits in hemiparkinsonian mice. Our data suggest that the $\mathrm{Nurr}^{+}$stage (middle stage) of neuronal differentiation is particularly suitable for grafting ESC-derived DA neurons. Moreover, global transcriptome analysis of progeny from each of the ESC reporter lines revealed expression of known midbrain DA neuron genes and also uncovered previously uncharacterized midbrain genes. These data demonstrate remarkable fate specificity of ESC-derived DA neurons and outline a sequential stage-specific ESC reporter line paradigm for in vivo gene discovery.
\end{abstract}

\section{Introduction}

Embryonic stem cells (ESCs) represent a potentially unlimited source of cells for applications in regenerative medicine. One promising strategy is the derivation of midbrain dopaminergic (DA) neurons for cell replacement therapy in Parkinson disease (PD). Several protocols have been developed to obtain ESC-derived midbrain DA neurons in vitro, though current technologies are far from perfect and cell preparations often contain contaminating non-DA cell populations and potentially tumorigenic cell types $(1,2)$. Furthermore, despite more than 40 years of research on developing DA cell replacement paradigms, many fundamental questions critical for effective clinical translation have remained unanswered, such as the stage of DA neuron development most appropriate for transplantation; whether other non-dopamine cell types within the graft, such as glia, are necessary for in vivo DA neuron survival and function; and how closely in vitro-generated cells match the properties of authentic midbrain DA neurons generated in vivo. The use of ESC technology has the potential to address all these questions and presents a virtually unlimited source of fully defined DA neurons.

One strategy to obtain highly enriched populations of midbrain DA neurons is the purification of ESC-derived progeny prior to transplantation through the use of fluorescence-activated cell

Authorship note: Elizabeth L. Calder and Sonja Kriks contributed equally to this work. Conflict of interest: The authors have declared that no conflict of interest exists. Citation for this article: J Clin Invest. 2012;122(8):2928-2939. doi:10.1172/JCI58767. sorting (FACS) $(3,4)$. BAC transgenesis has been developed as an efficient platform to produce cell-type specific GFP reporter mice (5) and has been adapted to engineer fluorescent ESC reporter lines in vitro (6). BACs carry more genetic information than conventional transgenes, which often results in more faithful expression and less susceptibility to positional effects. However, misexpression of BACs can occur, for example, due to fragmentation or due to the lack of important very distant regulatory elements. Gene targeting represents an alternative approach for generating mouse ESC (mESC) or human ESC (hESC) reporter lines with potentially even higher fidelity of expression. However, knockin reporter lines may show lower expression levels (single copy integration) and can potentially disrupt gene function (haploinsufficiency), both of which are less of a concern in BAC transgenesis. Here, we used 3 distinct BAC transgenic mESC reporter lines that mark the neural precursor stage (Hes5::GFP) (6), DA neurons at the stage of cell cycle exit (Nurr1::GFP), or fully differentiated DA neurons (Pitx3::YFP) (for review of markers, see ref. 7). Sequential expression of the 3 markers is thought to mimic the developmental progression of midbrain DA neurons in vivo. BAC transgenic reporter ESC lines were subjected to directed differentiation in vitro followed by FACS purification of reporter ${ }^{+}$cells at differentiation day 14-15. GFP ${ }^{+}$cells from the Hes5::GFP line showed an enrichment of neurons and glia, while reporter ${ }^{+}$cells from the Nurr1::GFP and Pitx3::YFP lines yielded nearly pure populations of neurons, with marker expression and functional properties consistent with the midbrain DA neuron identity. 

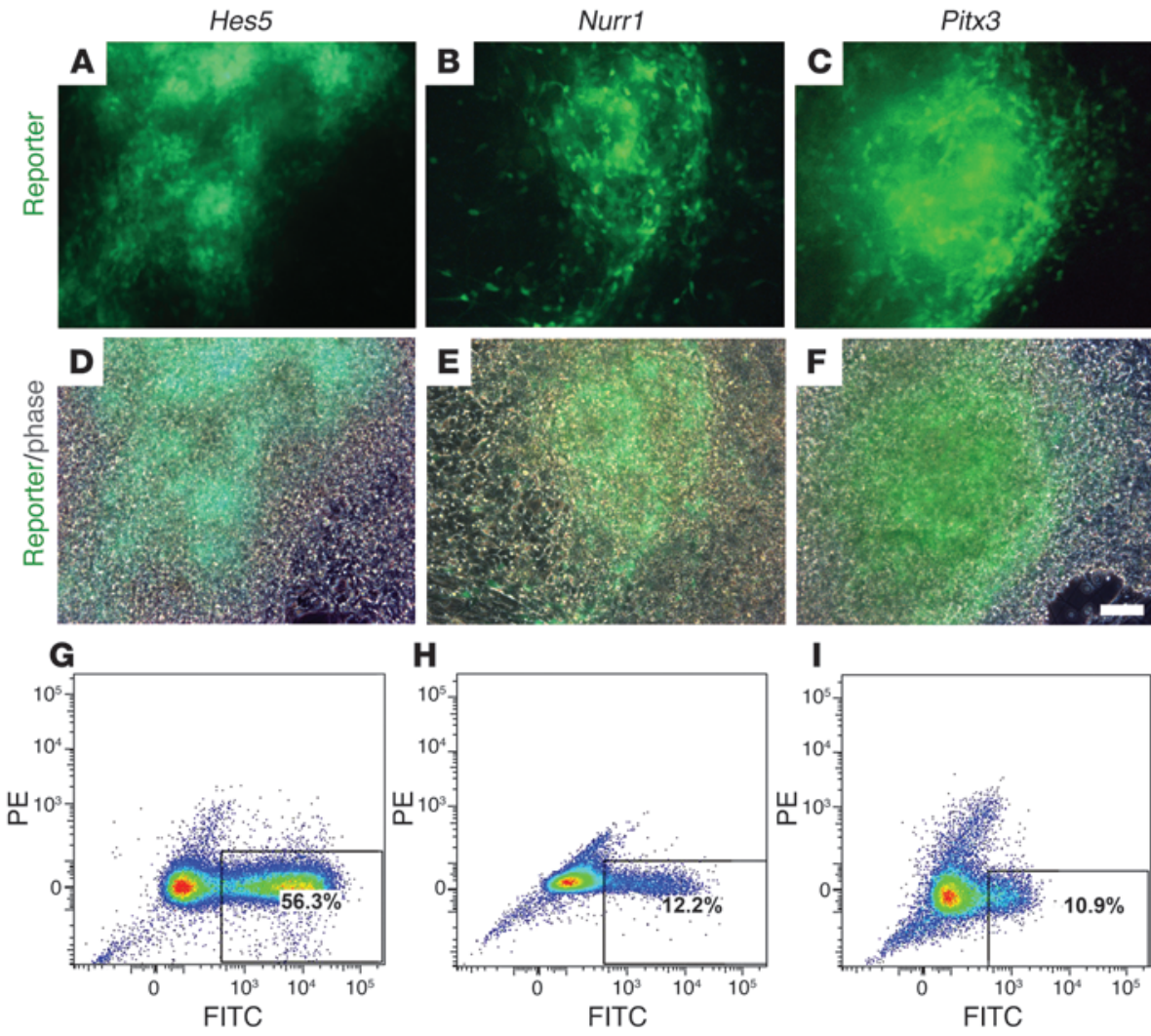

\section{Figure 1}

Characterization of reporter expression in the 3 BAC lines. $(\mathbf{A}-\mathbf{C})$ Live reporter expression on day 14 of differentiation. (D-F) Overlay of reporter expression and phase-contrast images. (G-I) FACS analysis for reporter expression at day 14 of differentiation plotted against PE and FITC channels. Numbers represent the percentage of positive cells. Scale bar: $50 \mu \mathrm{m}$.
Reporter $^{+}$progeny of all 3 lines were transplanted into 6-hydroxydopamine-lesioned (6-OHDA-lesioned) immunocompromised mice, and each population reliably induced functional recovery, while sham-grafted control animals did not show any behavioral improvement. Among the 3 reporter lines, both Pitx3::YFP and Nurr1::GFP yielded robust survival of nearly pure neuronal grafts, indicating that graft-derived glial cells are not essential for in vivo DA neuron survival. Transplantation of Nurr 1::GFP ${ }^{+}$cells resulted in the largest number of surviving DA neurons, thus defining the Nurr 1 stage as particularly suitable for in vivo DA neuron replacement therapies.

Comparative global transcriptome analysis revealed that in vitro-generated FACS-purified DA neurons express nearly all known markers of in vivo midbrain DA neurons. This remarkable authenticity further enabled the identification of what we believe are hereto unknown markers of midbrain DA neurons in the developing brains of both humans and mice. Our study is first to our knowledge to perform sequential stage-specific reporter line analysis (SSRLA) toward the identification of the stage most suitable for cell therapeutic intervention and establishes what we believe to be a novel paradigm for ESC-based gene discovery.

\section{Results}

Characterization and in vitro differentiation of BAC ESC reporter lines. In order to generate the Nurr 1::GFP and Pitx3::YFP lines, RP23236113 (GENSAT) and RP11-946K20 (CHORI) BACs, respectively, were retrofitted for mammalian selection and nucleofected into J1 mESCs, as previously reported for the Hes5::GFP BAC (6). G418-resistant colonies were expanded and differentiated toward the DA neuron lineage according to our previously pub- lished protocol (8), with minor modifications (see Methods), and screened for GFP or YFP expression. A total of 3 (out of 50) Nurr1::GFP and 2 (out of 22) Pitx3::YFP G418-resistant clones showed specific reporter expression at the DA neuron stage, as assessed by colocalization with NURR1 and PITX3 antibodies 24 hours after sorting, respectively (Supplemental Figure 1, A-C and E-G; supplemental material available online with this article; doi:10.1172/JCI58767DS1). Quantitative analysis confirmed high levels of coexpression of GFP antibody with the respective marker protein (Supplemental Figure 1, D and H). The low percentage of properly reporting G418-resistant clones is consistent with previously characterized BAC transgenic stem cell lines in both humans (9) and mice (6), with most clones showing no GFP expression and only very rare clones showing ectopic expression. Clones for each line were analyzed for stable, single-site, genomic integration of BAC DNA via FISH (Supplemental Figure 1, I-K). The lack of incorporation of BrdU within the Nurr1::GFP $P^{+}$and Pitx3::YFP+ cells confirmed a postmitotic neuron identity (data not shown). Expression of the reporter was first seen at day 6 of differentiation for the Hes5::GFP line, day 10 of differentiation for the Nurr1::GFP line, and day 12 of differentiation for the Pitx3::YFP line. At day 14, reporter expression was present in all 3 lines (Figure 1, A-F), and, upon FACS purification (Figure $1, \mathrm{G}-\mathrm{I})$, cells could be plated without feeder cell support at high concentration (50-100,000 cells in 1- to 2 - $\mu$ l droplets) onto Matrigel-treated chamber slides. Cells isolated by FACS were analyzed by qRT-PCR to confirm enrichment for their respective transcripts in reporter ${ }^{+}$cells compared with that in reporter ${ }^{-}$cells (Figure 2A). The Hes5::GFP line has previously been characterized to enrich 19.5 fold for Hes 5 mRNA (6). 

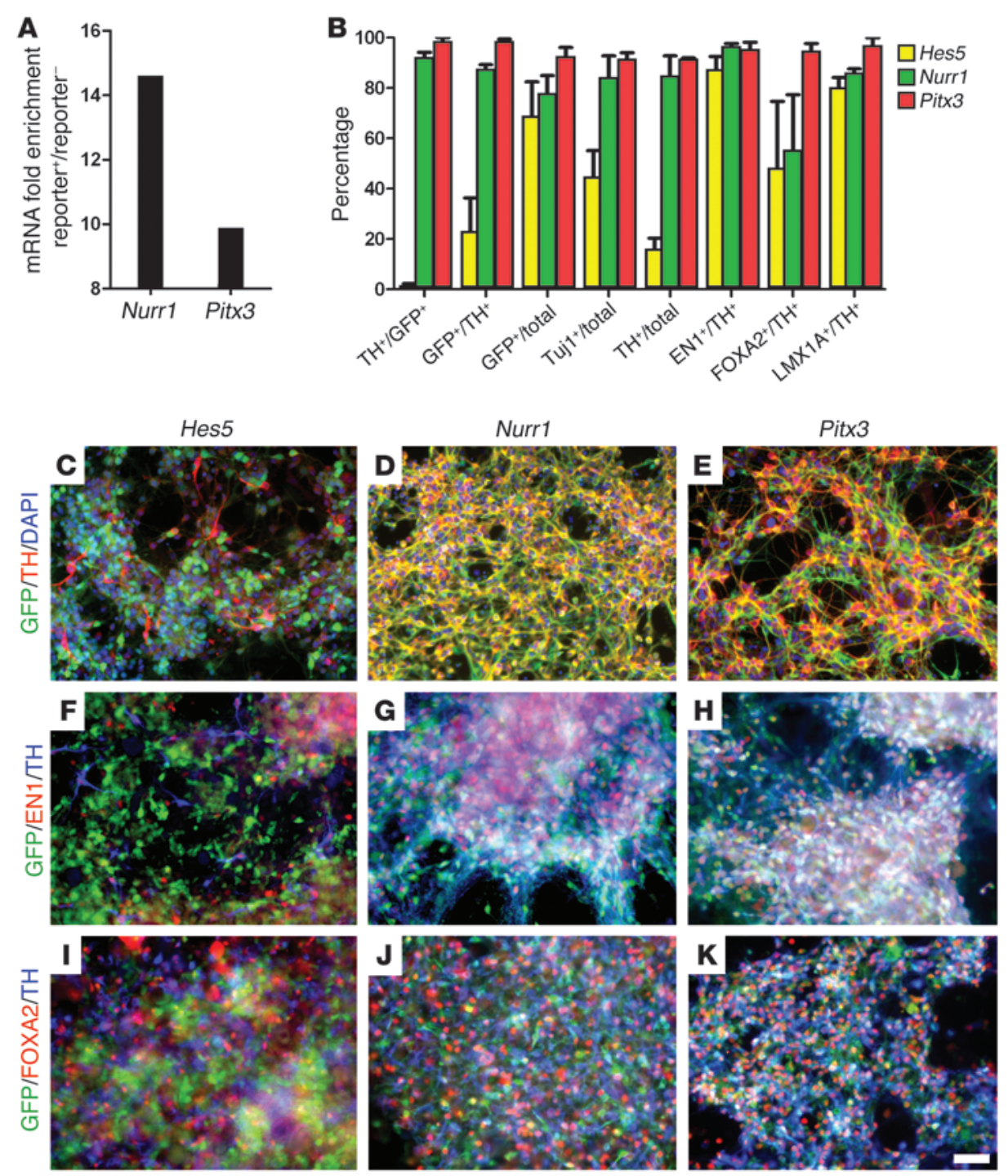

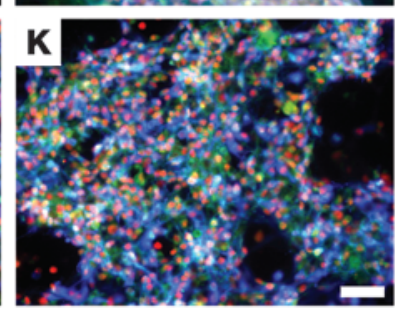

\section{Figure 2}

Short-term characterization of marker expression in FACS-purified cells. (A) qRT-PCR data showing enrichment of Nurr1 (14.6 fold) and Pitx3 (10.0 fold) in reporter ${ }^{+}$cells compared with that in reporter cells of the respective cell lines. (B-K) Immunocytochemical analysis of reporter ${ }^{+}$cells 24 hours after sorting. (B) Quantitative analysis in Hes5, Nurr1, and Pitx3 lines for coexpression of GFP and TH $\left(\mathrm{GFP}^{+} / \mathrm{TH}^{+}\right.$, $\mathrm{TH}^{+} / \mathrm{GFP}^{+}$), the percentages of $\mathrm{GFP}^{+}$, Tuj $1^{+}$, and $\mathrm{TH}^{+}$cells among total cells $\left(\mathrm{GFP}^{+} / \mathrm{DAPI}^{+}\right.$, Tuj $\left.1^{+} / \mathrm{DAPI}^{+}, \mathrm{TH}^{+} / \mathrm{DAPI}^{+}\right)$, and the colocalization of midbrain markers EN1, LMX1A, and FOXA2 in $\mathrm{TH}^{+}$

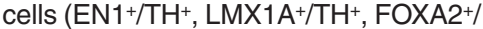
$\left.\mathrm{TH}^{+}\right) .(\mathbf{C}-\mathbf{K})$ Representative images of immunocytochemical marker analysis. Scale bar: $50 \mu \mathrm{m}$.
Immunocytochemical analysis 24 hours after sorting showed that the large majority of reporter ${ }^{+}$cells derived from the Nurr1::GFP and Pit $3::$ YFP lines, but not the Hes5::GFP line, were positive for DA neuron markers, such as tyrosine hydroxylase (TH; Figure 2, B-E). In contrast, unsorted cultures typically yield about $20 \% \mathrm{TH}^{+}$cells under identical differentiation conditions (2). $\mathrm{TH}^{+}$cells from all 3 reporter lines coexpressed the midbrain transcription factors EN1 (Figure 2, B and F-H) and LMX1A (Figure 2B and Supplemental Figure 1, L-N). In contrast, FOXA2, another transcription factor essential for the midbrain DA neuron lineage, was coexpressed in nearly all $\mathrm{TH}^{+}$cells derived from the Pitx3::YFP line but only in a subset of those derived from the Hes5::GFP and Nurr1::GFP lines (Figure 2, B and I-K). Analysis 7 days after sorting demonstrated that the Hes5::GFP line enriched for both neurons and glia (Figure 3A), while the Nurr1::GFP and Pitx3::YFP lines yielded nearly pure populations of neurons (Figure $3, \mathrm{~B}$ and $\mathrm{C}$ ), most of which coexpressed TH (Figure 3, D-F). While most Nurr1::GFP- and Pitx3::YFP-sorted cells retained reporter expression upon further in vitro differentiation, there was variability in the levels of expression, particularly in the Nurr 1 and Hes 5 lines. This may be due to the fact that Nurr1-and Hes5-positive cells, at the time of sorting, comprise a broader range of differentiation stages compared with those that are Pitx3-positive, whose onset of expression is initiated just around the time of sorting. Other potential reasons include differences between endogenous protein and BAC reporter expression and/or BAC reporter silencing. Regardless, these data demonstrate the extensive survival of FACS-purified reporter ${ }^{+}$neurons, even in the absence of glial feeder support. Upon further differentiation, reporter ${ }^{+}$cells isolated from the Nurr1::GFP and Pitx3::YFP lines developed long axons (Figure 3G) and exhibited electrophysiological properties compatible with the midbrain DA neuron identity (Figure $3 \mathrm{H}$ ), including firing multiple action potentials at moderate rates $(2-10 \mathrm{~Hz})$ in response to sustained depolarizing current injection. Together, these in vitro data support the use of BAC transgenic reporter ESC lines to generate and purify stage-specific populations of midbrain DA neurons.

In vivo analysis of FACS-purified midbrain DA neuron populations. We next tested whether FACS-purified populations can functionally engraft in vivo and induce behavioral recovery upon transplantation into the striatum of adult unilateral 6-OHDA-lesioned mice. 

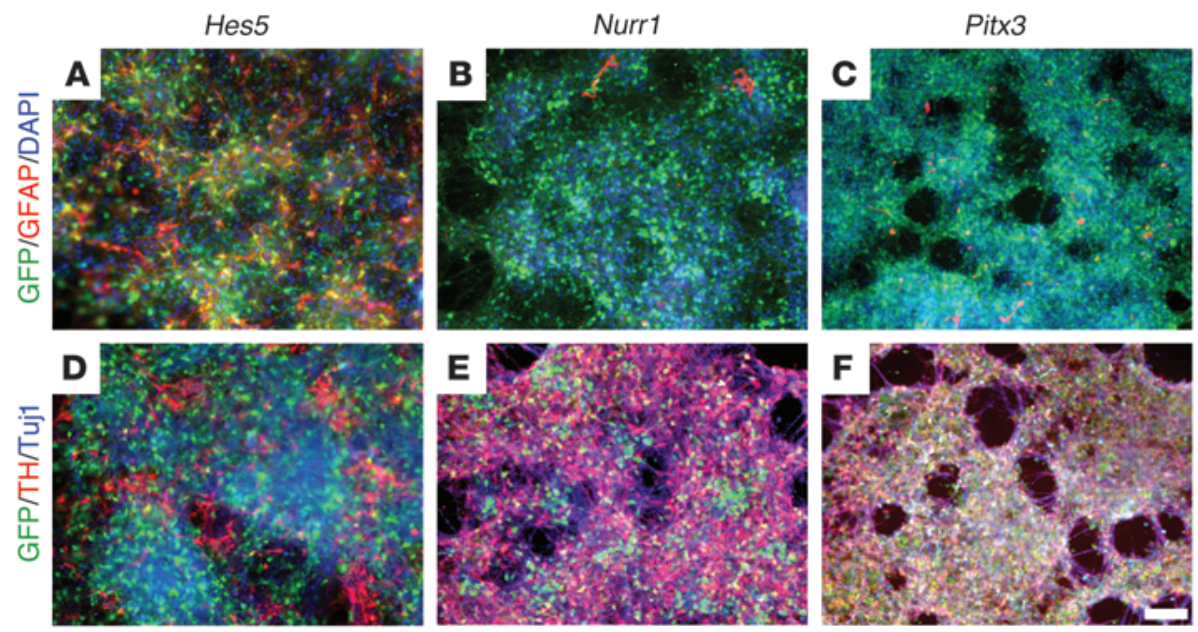

G

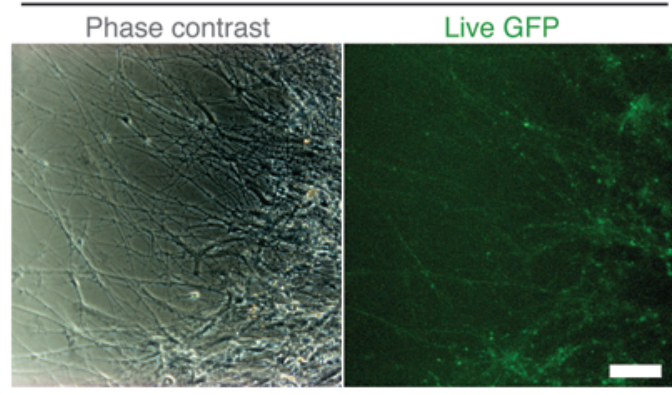

H

H Nurr1

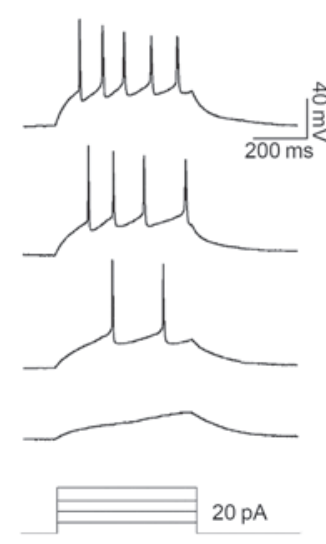

Pitx3

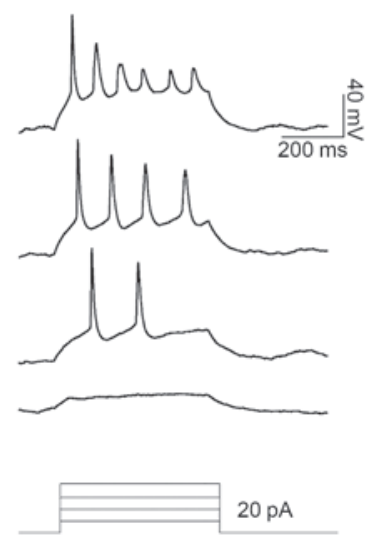

\section{Figure 3}

Long-term in vitro characterization of cells after sorting. (A-C) Immunocytochemical analysis for GFP, GFAP, and DAPI in the 3 lines. (D-F) Immunocytochemical analysis for GFP, TH, and Tuj1. (G) Phase-contrast and GFP expression in Nurr1::GFP+-sorted cells 6 days after replating. $(\mathbf{H})$ Whole-cell recordings in current clamp mode from Nurr1 and Pitx3 lines show neuronal-like excitability, with cells firing multiple action potentials at rates between 2 and $10 \mathrm{~Hz}$ and evidence of spike frequency adaptation ("accommodation"). Scale bar: $100 \mu \mathrm{m}$ (A-F); $40 \mu \mathrm{m}$ (G).

Animals were monitored for 3 independent behavioral parameters to quantify the extent of hemiparkinsonian symptoms, including amphetamine- and apomorphine-induced rotational asymmetry (ipsilateral and contralateral, respectively) and the cylinder test for determining ipsilateral paw preference during rearing. Mice with stable amphetamine-induced ipsilateral rotation scores ( $>5$ rotations/min) were selected for transplantation studies. Each of the 3 BAC reporter lines were each differentiated in vitro $(2,8)$ and sorted for their respective reporters prior to transplantation (day 14-15).

One challenge of transplanting mESC-derived DA neurons is the risk of tumor formation due to the presence of contaminating undifferentiated cells within the graft. Our laboratory has previously reported reduced frequency of tumor formation upon short-term replating of $\mathrm{mESC}$-derived DA neurons prior to transplantation (2). Here, we tested whether FACS purification of neural cell populations is sufficient to prevent tumor formation, even under adverse conditions such as (a) omitting the replating step, (b) grafting large cell numbers $(75,000-150,000$ cells/ $\mu 1$ for a total of 150,000-200,000 cells/brain), and (c) grafting into immunocompromised SCID hosts. Histological analysis 6 weeks after transplantation revealed large tumor-like structures in roughly $50 \%$ of Nurr $1:: G F P$ - and Pitx $3::$ YFP-grafted mice and $33.3 \%$ of Hes5::GFP-grafted mice (Supplemental Figure 2, A-C). Tumors were preferentially located in the cortex despite stereotactic targeting of the striatum, suggesting that the cortex may be particularly susceptible for tumor formation. Tumor-forming grafts were composed of mostly neural cells but also contained areas of cells expressing pluripotent markers and markers of mesendodermal lineages (Supplemental Figure 2, D and E). These teratoma-like components within some of the grafts suggested contamination with ESC-like populations. Using SSEA1-PE- or SSEA1-647-conjugated antibodies, we found between $0.1 \%$ and $0.8 \%$ contamination with SSEA $1^{+}$cells after the first round of sorting (this would equal between 175 and 1,600 cells in our grafts) (Supplemental Figure 3$)$. To determine whether SSEA $1^{+}$cells are responsible for tumor formation, we grafted 1,500 ( $n=3$ mice) and 15,000 $(n=3$ mice) SSEA1-PE ${ }^{+}$cells isolated at day 14 of differentiation into the striatum of SCID mice. All 6 animals developed large tumors within 2 weeks. These data illustrate that tumor formation is likely due to rare populations of contaminating undifferentiated SSEA $1^{+}$ 

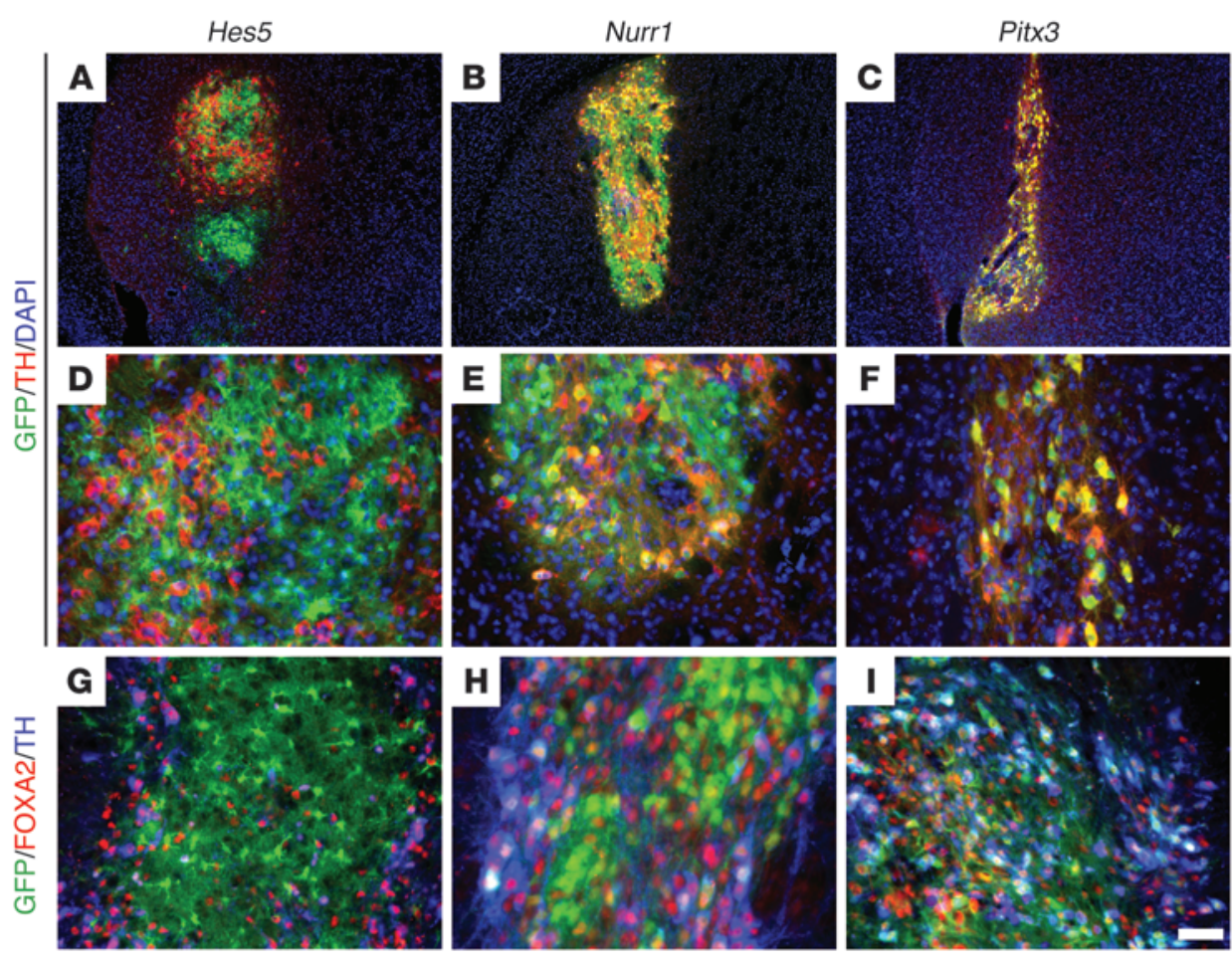

Figure 4

Characterization of grafts and behavioral analysis. (A-F) Immunohistochemical analysis of GFP, $\mathrm{TH}$, and DAPI expression 6 weeks after grafting (examples from single-sorted grafts). (G-I) Immunohistochemical analyses of GFP, FOXA2, and TH expression. Counts of $\mathrm{TH}^{+}$cells in the grafts plotted against total volume in $(\mathbf{J})$ singlesorted and (K) double-sorted cell grafts. Analysis of ipsilateral rotations at stages before and after grafting in mice grafted with (L) single-sorted cells $(n=4$ for each line) and (M) double-sorted cells $(n=3$ for each line), including sham-based $(n=4)$ and J1 nontransgenic $(n=3)$ controls. Scale bar: $200 \mu \mathrm{m}$ (A-C); 50 $\mu \mathrm{m}(\mathrm{D}-\mathrm{I}) .{ }^{*} P \leq 0.05$, Dunnett's test with Hes5 grafts as baseline group for $\mathbf{J}$ and Pitx3 grafts as baseline group for $\mathbf{K}, \mathbf{L}$, and $\mathbf{M}$. ${ }^{*} P \leq 0.0$, ${ }^{* \star} P \leq 0.005$, ANOVA analysis.
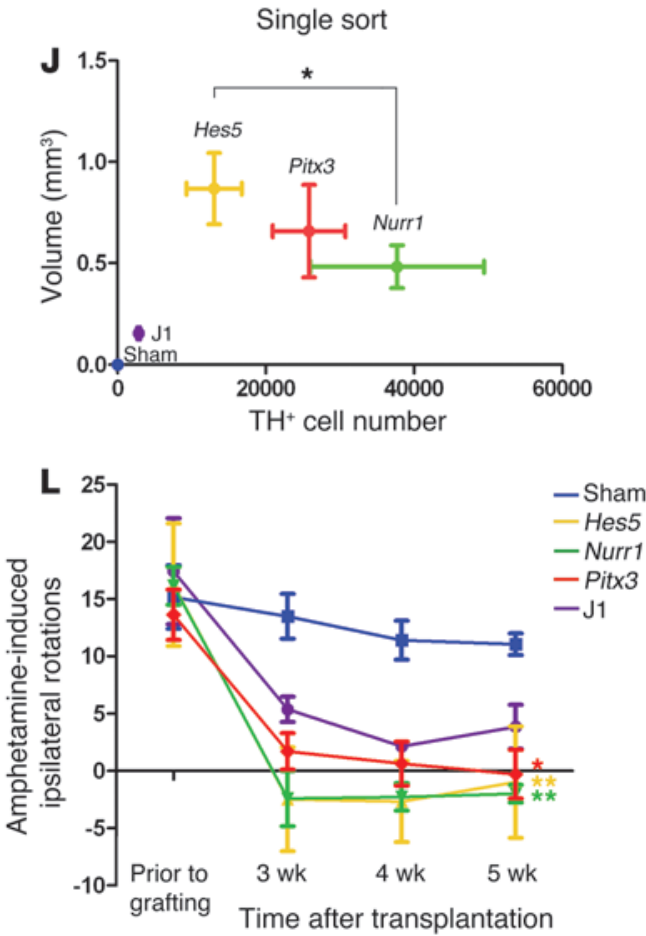

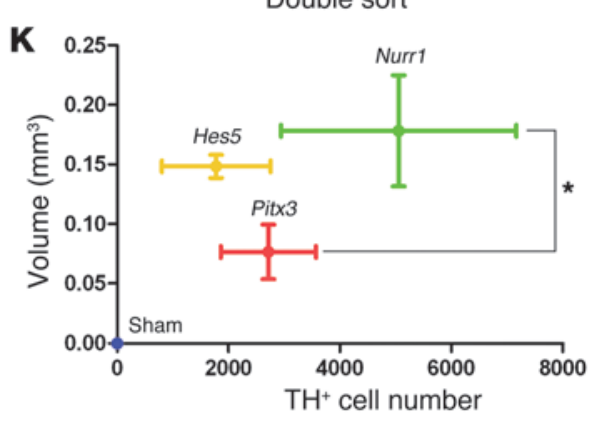

M

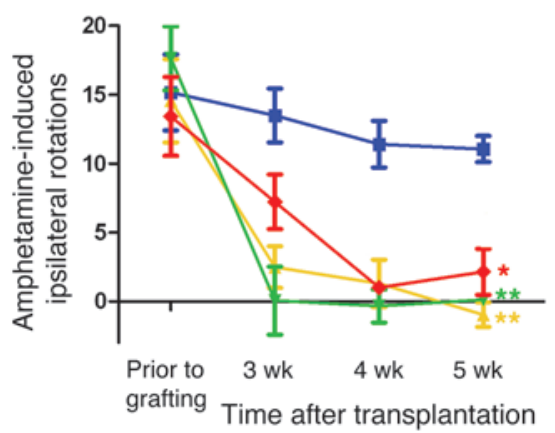

cells after sorting and that residual ESC-like cells at frequencies of less than $1 \%$ of total cells represent a significant tumor risk. Our sorting and grafting protocol was thus modified to include the SSEA1-647 antibody to remove these contaminants and thus reduced tumor formation by roughly $50 \%$ (4 out of 19 mice developed tumors) across the lines. Short-term replating prior to transplantation, a technique used previously (2), reduced the number of SSEA $1^{+}$cells from approximately $5 \%$ to $7 \%$ (no replating) to approximately $2 \%$ to $3 \%$ (after replating; Supplemental Figure 3). To address whether further enrichment of FACS-purified reporter ${ }^{+}$ cells can eliminate tumor risk, we resorted the reporter ${ }^{+}$cells after the first round of sorting and transplanted double-sorted reporter ${ }^{+}$ cells for each of the 3 reporter lines $(n=9)$. Under these conditions, tumor formation did not occur. 
A
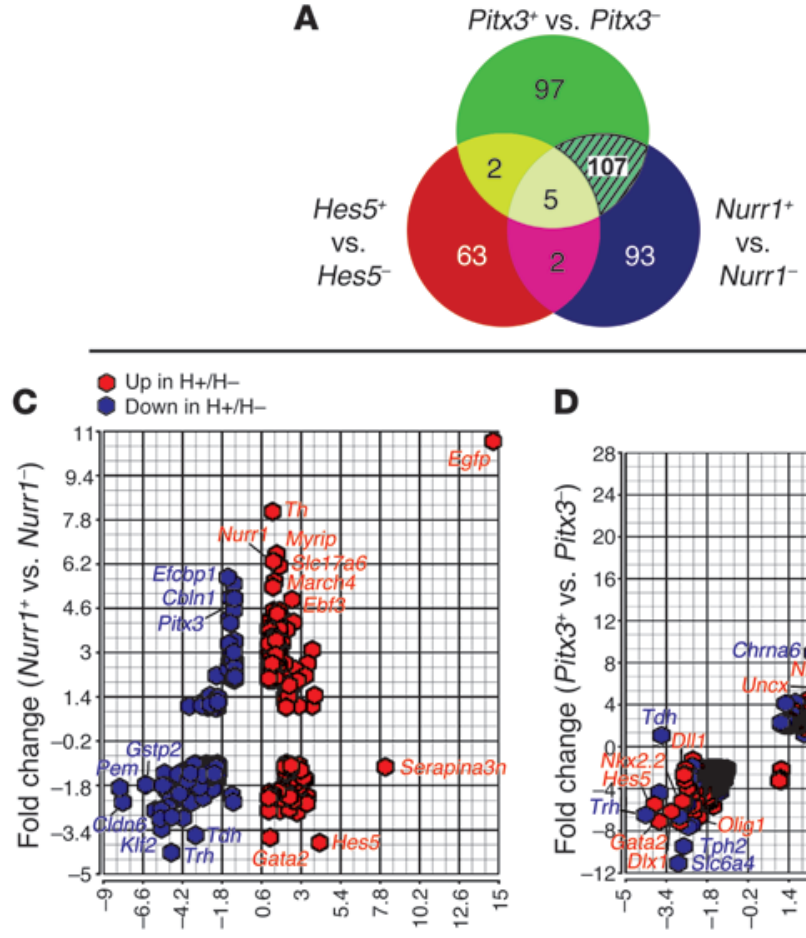

Fold change (Hes5 ${ }^{+}$vs. Hes5 $\left.5^{-}\right)$
D

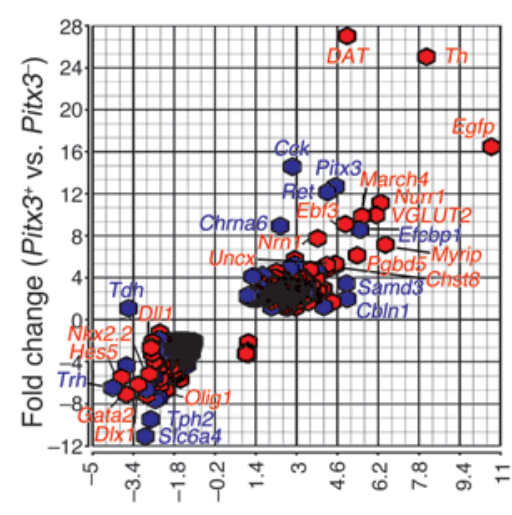

Fold change (Nurr1+ vs. Nurr1-)
B

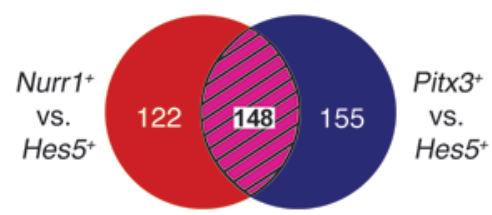

E

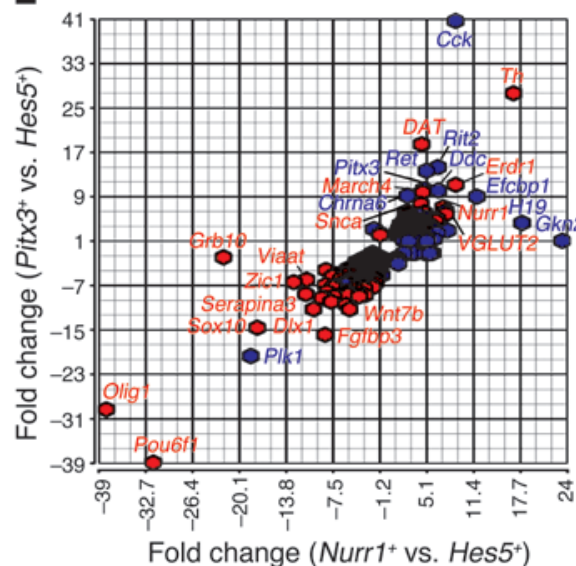

F NPNNPPNNHHHPHPNPH

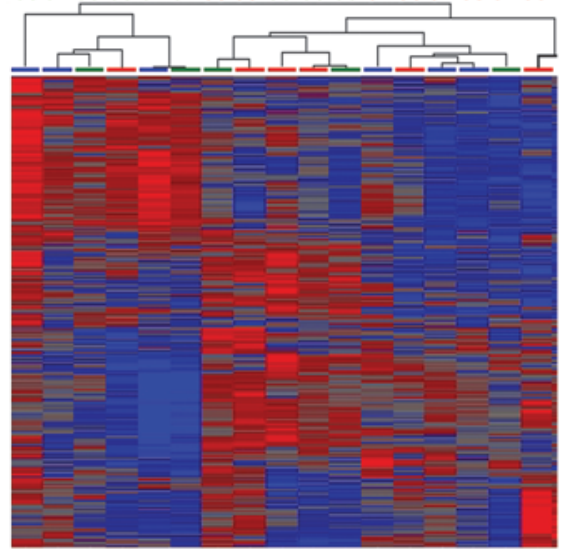

\section{Figure 5}

Microarray analysis of FACS-purified cell populations. (A) Venn diagram plot for significantly enriched (increased expression only) genes in intraline analysis, showing 107 genes common to both Nurr1::GFP+ and Pitx3::YFP+. (B) Venn diagram plot of significantly enriched genes in interline analysis, showing 148 genes common to both Nurr1::GFP+ and Pitx3::YFP+ cells in contrast to Hes5::GFP+ cells. (C-E) Scatter plots of significantly altered genes ( $\geq 2$ fold increased/decreased; $P \leq 0.05)$. Red boxes represent genes enriched at the Hes5 stage $(\mathrm{H}+/ \mathrm{H}-)$, while blue boxes represent genes that are decreased at that stage. (C) Intraline scatter plot of the 233 altered $\mathrm{H}+/ \mathrm{H}$ - genes ( $x$ axis) compared with the altered $232 \mathrm{~N}+/ \mathrm{N}-$ genes ( $y$ axis) (449 genes common to both). (D) Intraline scatter plot of the 232 altered $\mathrm{N}+/ \mathrm{N}-$ genes compared with the 556 altered $\mathrm{P}+/ \mathrm{P}-$ genes (656 genes common to both). (E) Interline scatter plot of the 586 altered $\mathrm{N}+/ \mathrm{H}+$ genes compared with the 1,203 altered $\mathrm{P}+/ \mathrm{H}+$ genes (1,355 genes common to both). (F) Dendrogram plot of all significantly altered genes $(P \leq 0.05)$ in all 3 reporter $^{+}$and reporter sorts across the 3 lines. H, Hes5; P, Pitx3; N, Nurr1.
A key goal of our study was to compare the efficiency of DA neuron engraftment among the 3 reporter lines in an effort to define the stage most suitable for cell replacement therapy. Analysis of the tumor-free single-sorted and all of the double-sorted grafts showed robust survival of $\mathrm{TH}^{+}$neurons in all 3 lines in comparison to similarly sorted (SSEA1-negative/propidium iodide-negative) J1 cells - the parental cell line of the transgenic lines (Figure 4, A-F). Single-sorted Hes5::GFP+ cells yielded slightly lower numbers of $\mathrm{TH}^{+}$cells in vivo $\left(13,006 \pm 3,734 \mathrm{TH}^{+}\right.$cells $)$as compared with those of grafts derived from the Nurr1::GFP $(37,697 \pm 11,709$ $\mathrm{TH}^{+}$cells $)$and Pitx $3:: Y F P\left(25,824 \pm 4,896 \mathrm{TH}^{+}\right.$cells $)$lines, but all were significantly higher than those of non-reporter-sorted J1 controls $\left(2,840 \pm 192 \mathrm{TH}^{+}\right.$cells $)$. Grafts from the Hes5::GFP line showed preferential localization of $\mathrm{TH}^{+}$cells to the graft periphery and contained a large number of $\mathrm{GFP}^{+} / \mathrm{GFAP}^{+}$astrocytes (Supplemental Figure 4A). In contrast, Nurr1::GFP and Pitx3::YFP grafts were composed of nearly homogenous $\mathrm{TH}^{+}$neurons that distributed evenly throughout the graft core (Supplemental Figure 4B) without any $\mathrm{GFP}^{+} / \mathrm{GFAP}^{+}$cells (data not shown). To determine whether $\mathrm{GFAP}^{+}$cells in the Nurr1 grafts came exclusively from the host, we generated subclones of the Nurr1::GFP and Hes5::GFP lines modified with a vector (10) designed to express RFP constitutively (Nurr1::GFP;UbC::RFP and Hes5::GFP;UbC::RFP). These lines were differentiated as above, and, at day 14 of differentiation, $\mathrm{GFP}^{+} / \mathrm{RFP}^{+}$cells were sorted and grafted into hemiparkinsonian mice. While the majority of $\mathrm{GFAP}^{+}$cells came from the host, in the Hes5::GFP;UbC::RFP grafts, we observed many more $\mathrm{GFAP}^{+}$/ $\mathrm{RFP}^{+}$cells within the graft than in the Nurr $1:: G F P ; U b C:: R F P$ grafts (Supplemental Figure 4C), which is consistent with our in vitro results (Figure 3, A and B).

The midbrain DA neuron identity of $\mathrm{TH}^{+}$cells in the grafts was confirmed by colabeling with FOXA2 (Figure 4, G-I) and Pitx3 
Table 1

Microarray data set for selected mDA and non-mDA neuron markers

\begin{tabular}{|c|c|c|c|}
\hline & \multirow[b]{2}{*}{ Gene } & \multicolumn{2}{|c|}{$\left(\mathrm{P}+\mathrm{N}_{+}\right)$vs. Hes5 ${ }^{+}$} \\
\hline & & $P$ value & Fold change \\
\hline \multirow[t]{5}{*}{ DA marker } & Th & 0.0014 & 21.53 \\
\hline & $D d c$ & 0.0014 & 8.21 \\
\hline & Vmat2 & 0.0281 & 3.34 \\
\hline & $D A T$ & 0.0397 & 9.02 \\
\hline & Cck & 0.0015 & 19.11 \\
\hline \multirow[t]{5}{*}{ mDA TFs } & Pitx3 & 0.0014 & 6.99 \\
\hline & Nurr1 & 0.0019 & 7.19 \\
\hline & Foxa2 & 0.0097 & 2.31 \\
\hline & En1 & 0.0033 & 3.51 \\
\hline & Lmx1a & 0.0286 & 5.42 \\
\hline \multirow[t]{4}{*}{ Others } & VGLUT2 & 0.0014 & 6.72 \\
\hline & Map2 & 0.0485 & 1.77 \\
\hline & Ret & 0.002 & 8.3 \\
\hline & Nkx2.2 & $2 \times 10^{-5}$ & -6.35 \\
\hline
\end{tabular}

mDA TF, midbrain-specific transcription factor.

(Supplemental Figure 5, A and B). Reporter ${ }^{+}$cells from both the Nurr1::GFP and Pitx3::YFP grafts also colabeled with GIRK2, a marker of substantia nigra (SN, also known as A9) type DA neurons, or calbindin, a marker expressed in postmitotic DA neurons of the ventral tegmental area (VTA, also known as A10), indicating that FACS-purified populations yielded both A9- and A10-type midbrain DA neurons in vivo (Supplemental Figure 5, C and D). Consistent with our in vitro results, we did not observe any cycling cells in the Nurr1 grafts, as evident by an absence of Ki67 staining (Supplemental Figure 5, E and F). The largest $\mathrm{TH}^{+}$cell numbers and densities were observed in the Nurr1::GFP line followed by the Pitx3::YFP line for both single- and double-sorted cells (Figure 4, $\mathrm{J}$ and $\mathrm{K}$ ). The significantly smaller number of $\mathrm{TH}^{+}$cells in grafts from double-sorted cells compared with that in single-sorted cells is likely due to increased mechanical stress upon sequential FACS and/or the lower total cell numbers grafted $\left(50 \times 10^{3}\right.$ to $100 \times 10^{3}$ cells in double-sorted cell preparations compared with $150 \times 10^{3}$ to $200 \times 10^{3}$ cells in single-sorted cell preparations).

Single-and double-sorted grafts provide behavioral recovery in hemiparkinsonian mice. While sham-grafted animals did not show any recovery in the amphetamine-induced ipsilateral rotation assay, animals grafted with FACS-purified cells from all 3 lines showed robust recovery, both for single-sorted (tumor-free) and doublesorted cell preparations (Figure 4, L and M, and Supplemental Figure 6A). Similarly, both single- and double-sorted grafts from all 3 lines showed improvements in apomorphine-induced contralateral rotation behavior (Supplemental Figure 6B), a parameter of dopamine hypersensitivity in the host striatum. Results from the cylinder test showed more variable results in graft-induced recovery (Supplemental Figure 6C). These data indicate that FACS-purified midbrain DA neuron progeny are capable of in vivo survival and complete restoration of amphetamine-induced rotation behavior in the 6-OHDA lesion model. Additionally, the near lack of graft-derived glia among the transplanted cells, in the case of Nurr 1::GFP and Pitx3::GFP grafts (Figure 3, B and C), suggests that ESC-derived neurons can co-opt host glia into the graft (Supplemental Figure 4, B and C).
Microarray analysis of the 3 reporter lines confirms cell identity and enables discovery of midbrain DA neuron-specific genes. The transplantation of purified postmitotic DA neurons instead of a more heterogeneous grafting population makes it imperative that the sorted cells exhibit a fully authentic midbrain DA neuron phenotype. In order to assess midbrain DA neuron identity in an unbiased manner, we performed global transcriptome analysis of FACS-purified populations for each of the 3 reporter lines at day 14 ( $n=3$ independent differentiations for each line). All raw data are available at GEO (accession no. GSE37446; http:// www.ncbi.nlm.nih.gov/geo/). We assessed midbrain DA neuronspecific gene expression profiles using 2 separate paradigms for data analysis: (a) intraline analysis - comparing reporter ${ }^{+}$with reporter- cells for each line; and (b) interline analysis - comparing individual reporter ${ }^{+}$fractions from each of the 3 reporter lines

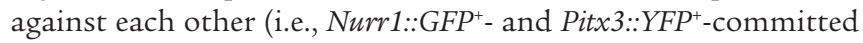
DA neurons compared with the Hes5::GFP+ precursor cell population). With the intraline analysis, we found 107 genes that were commonly enriched ( $\geq 2$ fold; $P \leq 0.05$ ) in the reporter ${ }^{+}$fractions of both the Nurr1 and Pitx3 lines (Figure 5A). With the interline analysis, there were 148 commonly enriched genes in the Nurr $1^{+}$ and Pit $x 3^{+}$cells compared with those in the Hes $5^{+}$population (Figure $5 \mathrm{~B}$ ). More than half of all putative midbrain DA neuron genes in the intraline analysis (Nurr $1^{+} /$Nurr $^{-}\left[\mathrm{N}^{+} / \mathrm{N}^{-}\right]$and Pitx $3^{+} /$Pitx $^{-}$ $\left[\mathrm{P}^{+} / \mathrm{P}^{-}\right]$only) overlapped with those of the interline analysis, for a total of 85 core transcripts, of which, 67 were upregulated and 18 were downregulated (Supplemental Table 1). Scatter plots of the significantly altered genes were established from both intraline (Figure 5, C and D) and interline (Figure 5E) analyses. Intraline analysis demonstrated that the only common gene upregulated in both $\mathrm{Hes}^{+} / \mathrm{Hes}^{-}(\mathrm{H}+/ \mathrm{H}-)$ and $\mathrm{N}+/ \mathrm{N}$ - cells was Gfp (Figure $5 \mathrm{C}$ ). In contrast, there was a strong correlation of genes regulated in $\mathrm{N}+/ \mathrm{N}$ - cells compared with those in $\mathrm{P}+/ \mathrm{P}-$ cells, with Th, DAT, and Gfp being the most highly enriched (Figure 5D and Supplemental Table 2). Similarly, the interline analysis showed a strong correla-

\section{Table 2}

Microarray data set for putative novel mDA neuron-related transcription factors and membrane-associated proteins

\begin{tabular}{|c|c|c|c|}
\hline & \multirow[b]{2}{*}{ Gene } & \multicolumn{2}{|c|}{$(\mathrm{P}+; \mathrm{N}+)$ vs. Hes5 ${ }^{+}$} \\
\hline & & $P$ value & Fold change \\
\hline \multirow[t]{4}{*}{ TFs } & Ebf3 & 0.0004 & 4.7 \\
\hline & Foxp2 & 0.0025 & 3.37 \\
\hline & Uncx4.1 & 0.0008 & 3.91 \\
\hline & $P b \times 1$ & 0.003 & 3.94 \\
\hline \multirow{12}{*}{ Memb. prot. } & Rit2 & 0.0023 & 9.72 \\
\hline & March4 & 0.0004 & 6.68 \\
\hline & Chrna6 & 0.0007 & 4.79 \\
\hline & Slc35d3 & 0.0003 & 4.4 \\
\hline & Cbln1 & 0.001 & 4.26 \\
\hline & Chst8 & 0.0005 & 3.79 \\
\hline & Chst1 & 0.0005 & 3.79 \\
\hline & Gucy2c & 0.0001 & 3.03 \\
\hline & Elmo1 & 0.0004 & 2.56 \\
\hline & Uts2r & 0.0002 & 2.54 \\
\hline & Opn3 & 0.0005 & 2.25 \\
\hline & Chrna5 & 0.0033 & 2.11 \\
\hline
\end{tabular}

TF, transcription factor; Memb. prot., membrane-associated proteins. 
UNCX4.1

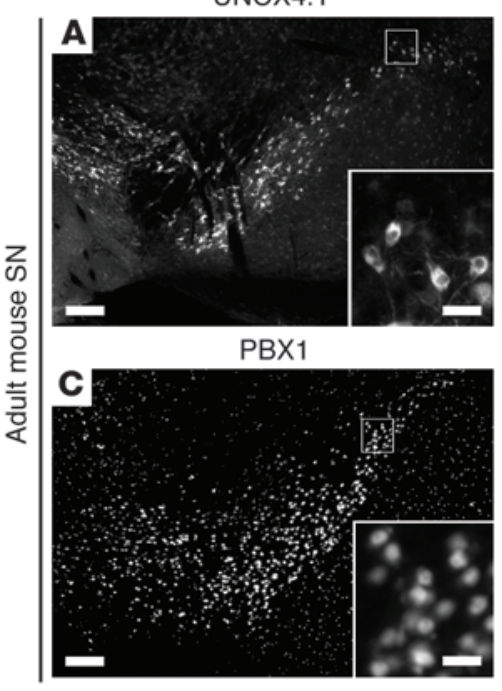

UNCX4.1/TH/DAPI

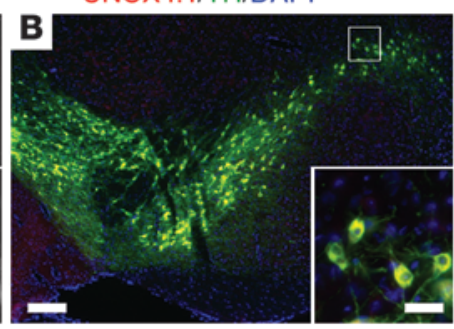

PBX1/TH/DAPI

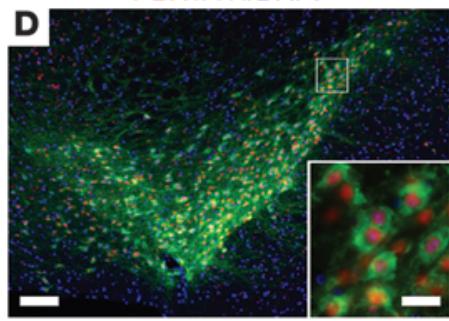

UNCX4.1/TH

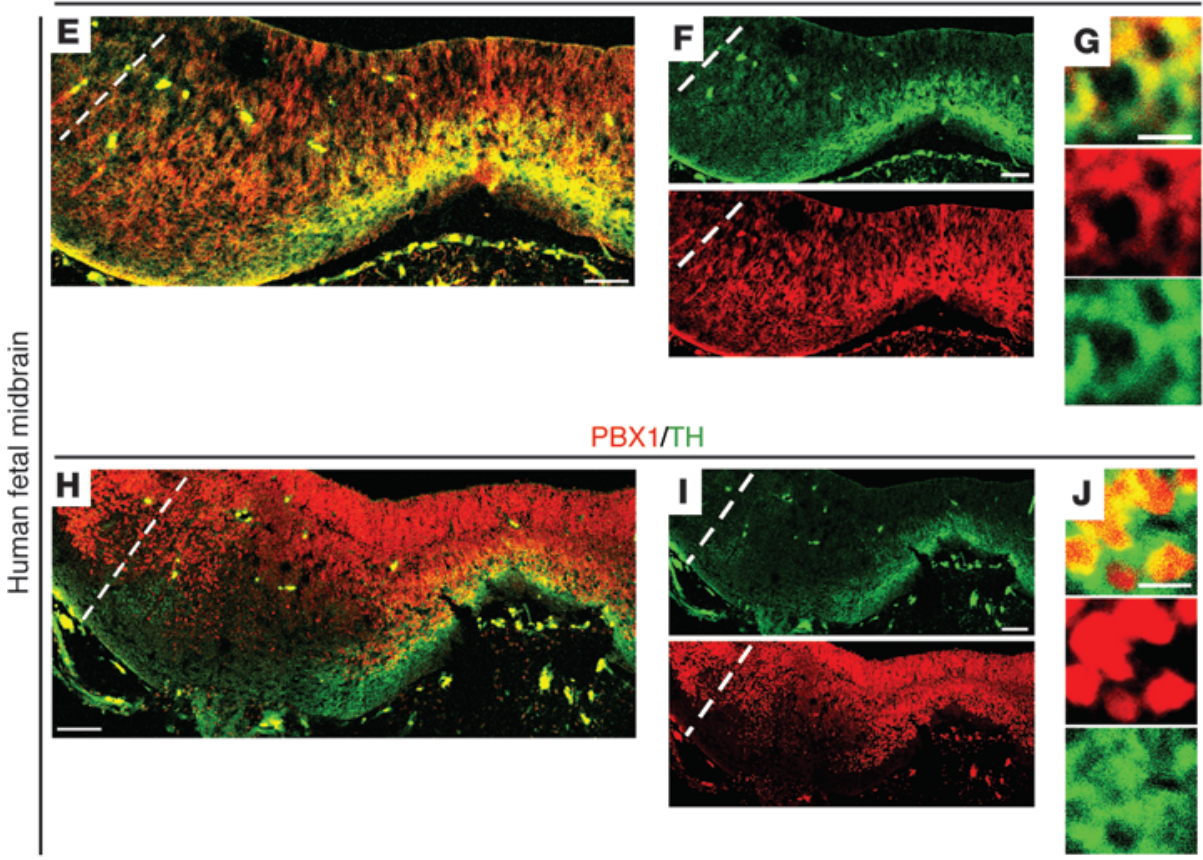

\section{Figure 6}

In vivo confirmation of UNCX4.1 and PBX1 expression in the adult mouse $\mathrm{SN}$ and human fetal midbrain (6-8 weeks after conception). Immunohistochemistry for UNCX4.1 ([A] UNCX4.1 in single channel; [B] UNCX4.1/TH/DAPI in merged image) and PBX1 ([C] PBX1 in single channel; [D] PBX1/TH/DAPI in merged image) in the adult mouse $\mathrm{SN}$. Immunohistochemistry in human fetal midbrain tissue for (E-G) UNCX4.1 and (H-J) PBX1 demonstrated similar perinuclear and nuclear staining patterns, respectively. Scale bar: $200 \mu \mathrm{m}(\mathbf{A}-\mathbf{D})$; $100 \mu \mathrm{m}(\mathbf{E}, \mathbf{F}, \mathbf{H}$, and I); $25 \mu \mathrm{m}(\mathbf{G}, \mathbf{J}$, and insets for A-D). tion for genes regulated in $\mathrm{Nurr}^{+} / \mathrm{Hes}^{+}(\mathrm{N}+/ \mathrm{H}+)$ cells compared with those in Pitx $3^{+} / \mathrm{Hes}^{+}(\mathrm{P}+/ \mathrm{H}+)$ cells, with Th and Cck being the most highly enriched and Pou6f1 and Olig1 being the most downregulated transcripts (Figure 5E and Supplemental Table 3). The similarities between the Nurr $1^{+}$and Pit $\times 3^{+}$fractions were further illustrated by unsupervised clustering of all significantly changed genes in a dendrogram that grouped all of the Nurr $1:: G F P^{+}$and Pitx $3:: Y_{F P}^{+}$samples together, while Hes5::GFP+ samples clustered with the all the reporter- fractions (Figure 5F).

Further analysis of the genes significantly enriched in the

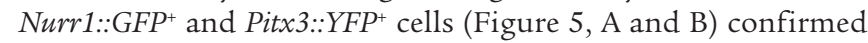
the expression of known midbrain DA neuron genes, including biochemical markers associated with DA synthesis and signaling, such as $T h, D d c$, Vmat2, and DAT, and midbrain-specific transcription factors, such as Pitx3, Nurr1 (also known as Nr4a2), Foxa2,
En1, and Lmx1a (Table 1). These data demonstrate the remarkable specificity of FACS-purified cell populations corresponding to the midbrain DA neuronal fate.

We next asked whether our microarray data might enable the identification of novel markers of midbrain DA neurons. In particular, we were interested in the identification of cell surface markers and novel transcriptional regulators of potential functional relevance. Based on average fold changes of $\mathrm{P}+/ \mathrm{H}+$ and $\mathrm{N}+/ \mathrm{H}+$ of the interline analysis $\left([\mathrm{P}+; \mathrm{N}+]\right.$ vs. Hes $\left.5^{+}\right)$, gene ontology analysis identified a total of 42 transcripts encoding genes associated with the cell membrane and 17 transcripts encoding transcription factors or transcriptional regulators that were differentially expressed at 2 fold or higher $(P<0.05)$ (Table 2 and Supplemental Table 4). To test specific expression of novel candidate midbrain DA neuron markers, we performed intraline and interline qRT-PCR analy- 
sis (Supplemental Figure 7A) and in vivo immunohistochemical analysis of the expression of transcription factors Uncx4.1 and $P b x 1$. Both genes showed specific in vivo expression in the adult mouse ventral midbrain. Uncx4.1 selectively marked $\mathrm{TH}^{+}$cells in the SN and VTA, with labeling being mostly perinuclear (Figure 6, A and B). Perinuclear staining for Uncx4.1 was surprising given the expected role of this gene as a transcription factor. However, perinuclear staining for Uncx4.1 has been previously observed in placental tissue, and perinuclear localization has been reported for other transcription factors such a CREB (following 6-OHDA lesioning; ref. 11). In contrast, $P b x 1$ showed strong nuclear localization in midbrain DA neurons but was not as exclusive to the midbrain DA neuron domain (Figure 6, C and D). Importantly, both UNCX4.1 and PBX1 were also expressed in the FOXA2 ${ }^{+} / \mathrm{TH}^{+}$ ventral domain of the developing human midbrain (6-8 weeks after conception; Figure 6, E-J, and Supplemental Figure 8). The conserved expression pattern of these transcription factors suggests that they could play a role in human midbrain DA neuron development and/or maintenance.

Another novel marker, NECAB1, a member of a family of neuronal $\mathrm{Ca}^{+}$binding proteins (12), was also expressed in the adult mouse midbrain but was localized to only a subset (the dorsal domain) of DA neurons in both the SN and VTA (Supplemental Figure 7B). C1ql1, a gene that has been shown to regulate synapse formation (13), was also found to be localized to DA neurons within the adult SN (Supplemental Figure 7C). In terms of cell surface markers, we found that Chrna6 (Table 2), a subunit of the nicotinic acetylcholine receptor (nAChR) that has previously been shown to be expressed in the adult mouse SN (14), was expressed within the developing midbrain in 3 separate mouse databases (ref. 15 and Supplemental Figure 9, A-D). This gene is interesting given the well-established link between tobacco use and decreased rates of PD and because radiolabeled ligands to this receptor have been used for visualization of the human midbrain by single-photon emission computed tomography (16). Upon further investigation (14), we found that another nAChR subunit, CHRNB3, was also expressed in the FOXA2/LMX1A domain of the developing human ventral midbrain (Supplemental Figure 9E). Although future studies will be needed to characterize the functional role of these DA neuron markers, our data demonstrate that SSRLA of mESCs can be used to identify genes expressed in human development.

\section{Discussion}

Numerous studies have demonstrated the use of ESC-derived DA neurons for grafting in animal models of PD (17); however, it has remained unclear which stage of differentiation and what particular population of cells is most effective at inducing functional benefits upon transplantation in vivo. Fetal tissue studies have focused on the grafting of ventral mesencephalic tissue isolated at a stage in which the majority of developing DA neurons are postmitotic, which is E12-E13 in mice (18) and E14-E15 (19) in rats. In human fetal grafting studies, increased survival of $\mathrm{TH}^{+}$neurons has been reported for tissue derived from embryos at 5 to 8 weeks after conception when using suspension grafts and up to 9 weeks after conception for solid grafts (20). In all of those cases, however, the grafted population was composed of a heterogeneous pool of cells at various stages of differentiation and typically contained less than $20 \%$ DA neurons (21). One recent study used purified DA neurons derived from a Pitx3::GFP plasmid reporter line established by gene targeting (4). The authors reported a requirement for coculture with primary astrocytes to achieve robust in vitro survival of FACSpurified DA neurons and observed less robust in vivo survival rates. Nevertheless, the study did demonstrate functional engraftment of purified DA neurons in at least a subset of animals (4).

In this study, we observed excellent in vitro and in vivo survival for DA neurons derived from both the Nurr1::GFP and Pitx3::YFP lines without astrocyte coculture, thus providing clear evidence that transplantation of purified early-stage DA neurons is a promising option for PD grafting. The requirement for double sorting to eliminate tumorigenic cells was associated with a lower survival rate of $\mathrm{TH}^{+}$cells. While animals with double-sorted grafts received half the number of cells compared with those with single-sorted grafts (due to our limited scalability), $\mathrm{TH}^{+}$cell survival in doublesorted grafts was 10 times lower. This lower DA neuron survival rate could be due to factors secreted by contaminating cells in single-sorted grafts or increased mechanical stress involved in the double-sorting process or point to a critical threshold of total cells needed for graft survival and integration. Despite the decreased survival rate, the number of DA neurons delivered via double sorting was sufficient to provide therapeutic benefits in our behavioral assays. It has been shown that as few as $400 \mathrm{TH}^{+}$neurons can provide up to $50 \%$ reduction in behavioral deficits of hemiparkinsonian rats 6 weeks after surgery $(22) . \mathrm{TH}^{+}$cell numbers in our study clearly surpassed this threshold in both single- and double-sorted populations, and we commonly observed contralateral rotations in our single-sorted grafts following amphetamine stimulation, a finding in often interpreted as overcompensation. Among the 3 stages of DA neuron development tested here, in vivo $\mathrm{TH}^{+}$cell yields were highest in reporter ${ }^{+}$cells from the Nurr $1:: G F P$ line, without evidence of reduced specificity in DA neuronal fate. Therefore, transplantation of purified early postmitotic DA neurons at the $\mathrm{Nurr}^{+}$stage may be a particularly promising approach for eventual clinical translation. However, it should be noted that recovery of behavioral deficits was not statistically significant in the cylinder or apomorphine tests. This could be due to various factors including limited fiber outgrowth of the DA neurons; low levels of DA release; or technical limitations of our study, such as measuring performance in only a single test both before and after grafting, low sample size, and limitations of the mouse as opposed to the more commonly used rat 6-OHDA model. However, in terms of recovery of amphetamine-induced motor deficits and overall DA neuron cell survival of single- and double-sorted grafts, we found that the Nurr1 stage of differentiation is ideal for grafting ESC-derived DA neurons.

Future studies will be needed to address the effect of glial cells, or lack thereof, at the time of grafting. Our data indicate that graft-derived DA neurons are surrounded by glia from the host. But currently it is unclear whether the host glia help or hinder DA neuron survival and function. In double-sorted cells, there was a trend toward a more robust behavioral recovery in $H e s 5:: G F P^{+}$ grafts compared with that in Pitx3::YFP ${ }^{+}$grafts, despite similar or higher numbers of $\mathrm{TH}^{+}$cells in the Pit 3 :: YFP group. One potential explanation could be that the presence of graft-derived astrocytes from the Hes5::GFP line promotes DA neuron function. Future studies will be needed to assess the survival and function of FACSpurified DA neurons in the presence or absence of astroglia.

The present findings underscore the need to graft populations highly enriched in neuronal fates in order to prevent tumor formation. When grafting cells at high concentrations in an immunocompromised host brain, we found that a percentage of less than 
$1 \%$ contamination $\left(175-1,600\right.$ SSEA $1^{+}$cells $)$at the time of grafting represents an unacceptable tumor risk. In addition to the double-sorting technique presented here, we could also largely prevent tumor formation by gating cells that were negative for SSEA1 expression during the initial reporter ${ }^{+}$cell sort, similar to previous work (23). We found the SSEA1-647 antibody to be particularly effective in reducing SSEA1 contaminants after sorting (Supplemental Figure 3). Attempts at reducing potentially tumorigenic cells prior to transplantation via short-term replating could decrease, but not fully eliminate, SSEA $1^{+}$cells (Supplemental Figure 3, C and F), which is in agreement with the more rare overgrowth behavior observed in previous work (2). Tumor formation from SSEA1 $1^{+}$-grafted cells occurred within 2 weeks following transplantation in our study, which is in contrast to the much slower time course observed in hESC-based neural grafts that more commonly show neural overgrowth rather than teratoma formation $(1,2)$. The differences in teratoma risk between mESCs and hESCs may be related to their respective pluripotent states, with hESCs being developmentally aligned to mouse epiblast stem cells (24), which are more primed for differentiation and exit of pluripotency. The lack of tumor formation at 6 weeks reported here indicates that double sorting is an effective approach at improving graft safety in the context of mESCs.

A factor that may have contributed to tumor formation in our single-sorted groups was the use of the immunocompromised mice. We observed that similar allografts in wild-type Sv129 hemiparkinsonian mice produced a much lower rate of tumor formation, with only 3 out of 46 animals exhibiting overgrowth. This indicates that there is a substantial risk of tumor formation, particularly when large numbers of mESC-derived neurons are grafted into the brains of immunocompromised mice. Future PD grafting studies will likely involve immunosuppression, suggesting that even under allograft conditions it will be important to proceed cautiously on the road toward future clinical translation of ESC-derived cell types.

A critical issue for DA neuron replacement paradigms in PD is the use of an appropriate cell source. While previous studies in mESCs have demonstrated in vivo functionality in murine PD models, there has been some concern that naive ESC-derived DA neurons may be less effective at alleviating behavioral symptoms as compared with fetal midbrain DA neurons. Several studies suggested that efficient DA neuron generation and engraftment occurs only upon transgenic modification of the cells using transcription factors such as NURR1 (25), LMX1A (26), or BCL-XL (27). This study shows that DA neurons derived from naive ESCs achieve robust behavioral recovery. Therefore, the variable results obtained in previous studies using naive ESC sources may have been caused by a low percentage of authentic DA neurons, rather than reflecting a true requirement for the expression of transgenic DA neuronal fate determinants.

In this study, the authenticity of FACS-purified midbrain DA neurons was confirmed at the molecular level for both Nurr1::GFP ${ }^{+}$and Pitx $3:: Y F P^{+}$cells. Nurr1 expression in the developing mouse brain is not exclusive to the midbrain DA neuron lineage (28). However, under the conditions of our differentiation protocol, Nurr1::GFP+ cells were consistent with the midbrain DA neuron phenotype based on both global transcriptome analysis and characterization of the grafted cells in vivo. Therefore, the incomplete marking of $\mathrm{TH}^{+}$cells by FOXA2 upon replating Nurr 1::GFP+ cells after sorting (Figure 2, B and J) likely reflects transient downregulation of the transcription factor, rather than alternative fate choice.

Gene discovery via the 3 reporter lines identified several relatively novel transcriptional regulators shown to be localized to the ventral midbrain, such as Foxp2 (29) and Ebf3 (30). The transcription factors, Uncx4.1 (31) and Pbx1, were confirmed via qRT-PCR (Supplemental Figure 7A), with Uncx4.1 being enriched under both paradigms and $P b x 1$ being enriched only under the intraline analysis. Supporting this observation, $P b x 1$ expression was found throughout the E10.5 mouse midbrain (Supplemental Figure 7D) and had a much broader domain than UNCX4.1 in the developing human midbrain (Figure $6 \mathrm{H}$ ), therefore suggesting a broader role for this transcription factor in CNS development. However, these genes continue to be expressed in the adult SN (Figure 6, A-D) and therefore are particularly attractive for future studies aimed at exploring the potential functional roles for these transcriptional regulators in midbrain DA neuron specification and/or maintenance. Additionally, the ability to purify midbrain DA neurons from hESC cultures will be necessary for any clinical translation, and therefore it is encouraging that CHRNA6 and CHRNB3 are cell surface markers expressed in the developing mouse and human midbrain, respectively (Supplemental Figure 9). Furthermore, a recent study has also confirmed the midbrain DA neuron specificity of the most significant cell surface marker gene on our gene list, Gucy2c (32) (Table 2 and Supplemental Tables 1-4). So while our data clearly demonstrate the applicability of SSRLA toward gene discovery, it would be interesting to compare our approach head-to-head with alternative approaches such as the use of transcription factor-driven lineage selection (33) or FACSbased isolation of primary DA neurons.

In conclusion, our study emphasizes the importance of identifying the appropriate cell type and differentiation stage in achieving safe and efficacious DA neuron engraftment. We found that early postmitotic DA neurons at the Nurr $1^{+}$or later stage represent a promising cell source for future translational studies. The use of BAC transgenic reporter lines may not be suitable for human clinical translation due to the need for transgene insertion and reporter gene expression. However, our profiling studies present multiple candidate surface markers that may enable comparable antibodymediated cell isolation strategies. The ultimate goal for translation may be, similar to that of drug-based therapies, to establish fully characterized, scalable, and ready-to-use populations of NURR1stage DA neurons that can be properly dosed and standardized for therapeutic applications. While many hurdles remain on the road toward this goal, we recently described a novel strategy for deriving midbrain DA neurons from hESCs that resulted in excellent in vivo survival and function (34). The choice of DA neuron differentiation stage used in this study was influenced by the current BAC reporter data, as we specifically aimed at transplanting hESC-derived DA neurons at the Nurr 1 expression stage. However, formal comparisons using hESC-based BAC or knockin reporter lines will be required to formally address these questions in purified human cells. While DA neuron replacement in PD represents a symptomatic treatment unlikely to affect all disease-related symptoms, access to pure populations of engraftable DA neurons will be a major step forward toward testing the full potential of DA neuron replacement therapies in PD. Finally, we believe that SSRLA is a powerful application of ESCs for gene discovery that could be used for generating refined genetic signatures in other specific ESC-derived cell types. 


\section{Methods}

BAC transgenic ESC line production. RP23-236I13 (GENSAT-modified) BAC for NURR1 and RP11-946K20 (Children's Hospital Oakland Research Institute; YFP recombineering into the entire coding sequence was performed by S. Kriks according to a previously described protocol; ref. 6) BAC for PITX3 were retrofitted with a Kan/G418 cassette for mammalian selection according to protocol (6). Purified DNA was produced with the PSI $\Psi$ Clone BAC DNA Kit according to the manufacturer's protocol and nucleofected into $6 \times 10^{6}$ cells as previously described (6). Nucleofected cells were plated onto Neo-resistant mouse embryonic fibroblasts (Globalstem) for 2 days, upon which G418 selection was performed at a concentration of $200 \mu \mathrm{g} / \mathrm{ml}$ for 7 to 10 days. Colonies were manually picked and expanded clonally and differentiated in 6-well plates according to a previously described protocol (8). Reporter ${ }^{+}$clones (observed at $\sim$ day 10 for NURR1 and day 12 for PITX3 lines) were further characterized for proper protein expression in vitro using the rabbit anti-NURR1 antibody (Perseus Proteomics; 1:1,000) and rabbit anti-PITX3 antibody (Zymed; 1:100) to double stain with GFP (Abcam; 1:1,000). Upon confirmation of proper protein expression, reporter ${ }^{+}$colonies were differentiated at large scale for 2 weeks, reporter $^{+}$and reporter cells were FACS-purified, and RNA was isolated in TRIzoL (Invitrogen) according to the manufacturer's protocol. qRT-PCR was then performed for each lines' corresponding RNA enrichment at the Memorial Sloan-Kettering Cancer Center (MSKCC) Genomics Core Lab using the housekeeping gene HPRT to normalize the data transcripts. BAC FISH was performed with purified BAC DNA (see above) and submitted to the Molecular Cytogenetics core facility. The Nurr1::GFP;UbC::RFP and Hes5::GFP;UbC::RFP cell lines were clonally selected after viral transduction with a modified plasmid driving RFP under the ubiquitin C promoter (10).

mESC culture, differentiation, and FACS preparation. J1 mESCs were grown on mouse embryonic fibroblasts in mESC medium (knockout DMEM, 20\% FBS, $2 \mathrm{mM}$ glutamine, $0.1 \mathrm{mM}$ MEM-nonessential amino acids, and $55 \mu \mathrm{M} \beta$-mercaptoethanol) supplemented with 1,400 U/ml LIF (ESGRO, Invitrogen). Differentiations for grafting and FACS were performed under a modified version of the MS5-based protocol previously reported (8). Briefly, ESCs were trypsinized and plated onto a dense MS5 feeder layer at a concentration of 20,000 cells per $10-\mathrm{cm}$ dish. The same protocol was applied, except using a different sonic hedgehog (SHH), C25II SHH (R\&D Systems) at $50 \mathrm{ng} / \mu \mathrm{l}$, and the whole protocol was shifted 1 day earlier (neural induction as day 4).

Initial sorting methods consisted of dissociation via resuspension in HBSS with $0.25 \%$ trypsin $(1: 100)$ for 1 hour at $37^{\circ} \mathrm{C}$ and manual trituration and resuspension in N2 with propidium iodide $(2 \mu \mathrm{g} / \mathrm{ml})$. Propidium iodide-negative cells were plotted for PE and FITC, and cells were caught into FBS. After the observation of tumors, cells were dissociated in accutase for 45 minutes at $37^{\circ} \mathrm{C}$, triturated, resuspended in $0.1 \% \mathrm{BSA} / \mathrm{PBS}$ and SSEA1-PE antibody (BD Pharmingen) for 20 minutes on ice, washed with PBS, resuspended in $0.1 \%$ BSA/PBS with $25 \mu \mathrm{M}$ HEPES and 7-AAD (BD Pharmingen, catalog no. 559925) ( $\mathrm{PBS}^{+}$), and caught in $\mathrm{N} 2$ medium. However, our best sort results, as assayed by SSEA1 levels after sorting, occurred when we replaced the SSEA1-PE with the SSEA1-647 antibody, as they use different lasers for their analysis (compensation is not necessary). All graftings were performed under propidium iodide-negative- and SSEA1-647-negative-gated conditions. Double sorting was performed by spinning down the reporter-sorted cells and resuspending them in $\mathrm{PBS}^{+}$. All cells for grafting and in vitro analysis were resuspended in N2 with BDNF $(20 \mathrm{ng} / \mathrm{ml})$ and ascorbic acid $(200 \mu \mathrm{M})$ at a concentration of between 50,000 and 100,000 cells per $\mu$ l. For in vitro analysis, 1 - to $2-\mu 1$ drops were spread onto PO/Lam- or Matrigel-treated (according to the manufacturer's protocol) Permanox chamber slides (Labtek) for 5 minutes, resuspended in N2/BDNF/AA, and analyzed after 24 hours or 7 days.
Lesioning and grafting. Fox Chase SCID beige mice (Charles River Laboratories) were housed and treated according to the MSKCC IACUC and NIH guidelines. At 6 to 8 weeks of age, mice were anesthetized with ketamine/ xylazine (Fort Dodge) or pentobarbital (Nembutal, Abbot Laboratories), and hemiparkinsonian lesions were performed according to a previously described protocol (2). Briefly, unilateral stereotactic injections of 6-OHDA (Sigma-Aldrich) were made in the striatum at the following coordinates: anteroposterior $[\mathrm{AP}],+0.5$; mediolateral $[\mathrm{ML}],-1.8$; dorsoventral [DV], -3.2 . Transplantation of 150,000 to 200,000 cells, at a concentration of 75,000 to 100,000 cells per $\mu$ l, was performed with a Hamilton syringe (26 gauge) at a rate of $1 \mu \mathrm{l}$ per minute at the following coordinates: $\mathrm{AP},+0.5$; $\mathrm{ML},-2.0 ; \mathrm{DV},-3.3$. Animals recovered for 3 weeks before behavioral testing.

Behavioral analysis. All behavioral tests were performed 2 weeks after lesioning and 3 weeks after grafting of cells and in the same order. Three separate amphetamine tests were performed weekly according to the previously described protocol (2). Briefly, 3 weeks after grafting, mice were injected with $10 \mathrm{mg} / \mathrm{kg}$ D-amphetamine sulfate (Sigma-Aldrich) intraperitoneally once a week for 3 weeks. Ten minutes after injection, mice were videotaped in a bowl for 30 minutes and scored via ipsilateral (positive) or contralateral (negative) rotations. After the final amphetamine test, mice underwent a single cylinder test 1 week later to test behavioral abnormalities when mice explore a novel environment (35), which was performed according to a previously described modified protocol (2). Briefly, mice were placed in a new cage, and 20 rearing observations were analyzed for paw placement on the wall of the cage. This assay is a measurement of forelimb akinesia, as ipsilateral paw placement is preferred in lesioned mice in contrast to contralateral and simultaneous paw placements. Apomorphine tests were performed the following day (1 week before cell grafting and for 7 weeks after grafting) similarly to amphetamine injections, except R-Apomorphine hydrochloride hemihydrate (Sigma-Aldrich) was dissolved in $2 \mathrm{mg} / \mathrm{ml}$ ascorbic acid in water (shaken at $37^{\circ} \mathrm{C}$ for 30 minutes) and injected at $40 \mathrm{mg} / \mathrm{kg}$. Contralateral rotations were scored as positive in this case and ipsilateral were scored as negative.

Electrophysiological analysis. After sorting, high-density cells were plated on Matrigel-treated glass coverslips and cultured in N2/AA/BDNF for 7 days. Resting membrane potentials from Nurr 1 cells were $-43 \pm 2 \mathrm{mV}$, with input resistance of $1.6 \pm 0.2 \mathrm{GOhm}$. Twenty-four out of twenty-eight cells from Nurr 1 coverslips fired action potentials in response to depolarizing current injection from $-60 \mathrm{mV}$. The resting membrane potential from Pitx 3 cells was $-38 \pm 2 \mathrm{mV}$, with input resistance of $1.6 \pm 0.2 \mathrm{GOhm}$. All 14 cells from Pitx 3 coverslips fired action potentials in response to current injection.

Immunofluorescence and microscopy. Mice were given a lethal dose of pentobarbital and transcardially perfused with PBS followed by $4 \%$ paraformaldehyde. Brains were removed and fixed overnight at $4^{\circ} \mathrm{C}$ and then transferred to $30 \%$ sucrose overnight. Brains were embedded in O.C.T. (Tissue-Tek) and stored at $-80^{\circ} \mathrm{C}$ until serial cryosectioning at 30 microns in 5 bottles. For fluorescence immunohistochemistry, sections were blocked in $10 \%$ normal goat serum (NGS; Gibco) with $0.2 \%$ Triton X-100 (Triton was omitted for surface antigens) for 30 minutes at room temperature. Primary antibodies were applied overnight in $2 \%$ NGS (1\% BSA for FOXA2 staining) at $4{ }^{\circ} \mathrm{C}$, followed by appropriate fluorochrome-conjugated secondary antibodies (Alexa Fluor conjugates; Molecular Probes) for 1 hour at room temperature. Slides were then washed and counterstained with Vectashield with DAPI (Vector Laboratories). Primary antibodies included rabbit antiTH (1:200; Pel Freez Biologicals), mouse anti-TH2 (1:1,000; Sigma-Aldrich), rabbit anti-GFAP (1:1,000; Dako), rabbit anti-LMX1A (1:2,000; Millipore), goat anti-FOXA2 (1:100; Santa Cruz Biotechnology Inc.), rabbit anti-PBX1 (1:500; Cell Signaling Technology), rabbit anti-GIRK2 (1:80; Alomone Labs), rabbit anti-NECAB1 (1:1,000; Sigma-Aldrich), mouse anti-Calbindin (1:500, Abcam), mouse anti-CHRNB3 (1:500; Sigma-Aldrich), rabbit 
anti-UNCX4.1 (1:100; Sigma-Aldrich), and rabbit anti-PITX3 (a gift from the laboratory of M.P. Smidt). Immunocytochemistry for in vitro characterization of midbrain DA neuronal fate included both polyclonal and monoclonal TH antibodies (see above) and mouse anti-Engrailed (1:100; clone 4G11, DSHB) antibodies. Human fetal mesencephalic tissue was collected from routine terminations of pregnancies (6-8 weeks after conception, determined by crown-rump length), with approval of the Swedish national board of health and welfare (Socialstyrelsen, Dnr. 23 11667/2008 and Dnr. 23 2981/2009).

Microarray analysis. mRNA transcriptome analyses were performed using Illumina Mouse-6 BeadChip technology for mRNA comparisons of 3 separate sorts for the Hes5::GFP $P^{+/}$, Nurr1::GFP ${ }^{+/}$, and Pitx $3:: \mathrm{YFP}^{+/-}$populations. Data were analyzed using Partek software (http://www.partek. $\mathrm{com} /$ ). Significance was based on an ANOVA analysis of all sorted populations, and significant gene lists were created under the criteria of an unadjusted $P$ value of $\leq 0.05$. Only transcripts enriched or depleted more than 2 fold were analyzed.

Quantification and statistical analysis. The number of surviving $\mathrm{TH}^{+}$neurons was assessed using stereological methods. Uniform random sampling was performed to obtain sections for graft quantification. Stereological software (Stereo Investigator, v6.0; Microbrightfield) was used to design and implement optical fractionator probes at a Gundersen-Jensen coefficient of error of 0.05. Data throughout the paper are expressed as average \pm SEM.
Statistical analysis for behavioral data at various time points after transplantation was performed by 1-way ANOVA.

Study approval. All mouse in vivo studies were performed following NIH guidelines and were approved by the local IACUC (MSKCC, New York, New York, USA).

\section{Acknowledgments}

We are grateful for excellent technical support from the Molecular Cytogenetics Core, the SKI Stem Cell Facility, Flow Cytometry, and the Genomics Core Laboratories at MSKCC. We also would like to thank Dimitris Placantonakis, Stuart Chambers, Gabsang Lee, and Agnete Kirkeby for helpful discussions on the manuscript. M. Parmar is funded by Swedish Research Council. This work was supported by the Starr Foundation, by the European Commission project NeuroStemCell, and by grant support from NINDS (NS052671).

Received for publication May 2, 2011, and accepted in revised form May 16, 2012.

Address correspondence to: Lorenz Studer, Developmental Biology, 1275 York Ave., Box 256, New York, New York 10065, USA. Phone: 212.639.6126; Fax: 212.717.3642; E-mail: HUstuderl@mskcc.org.
1. Roy NS, Cleren C, Singh SK, Yang L, Beal MF, Goldman SA. Functional engraftment of human ES cell-derived dopaminergic neurons enriched by coculture with telomerase-immortalized midbrain astrocytes. Nat Med. 2006;12(11):1259-1268.

2. Tabar $\mathrm{V}$, et al. Therapeutic cloning in individual parkinsonian mice. Nat Med. 2008;14(4):379-381.

3. Pruszak J, Sonntag KC, Aung MH, Sanchez-Pernaute $\mathrm{R}$, Isacson $\mathrm{O}$. Markers and methods for cell sorting of human embryonic stem cell-derived neural cell populations. Stem Cells. 2007;25(9):2257-2268.

4. Hedlund E, et al. Embryonic stem cell-derived Pitx3-enhanced green fluorescent protein midbrain dopamine neurons survive enrichment by fluorescence-activated cell sorting and function in an animal model of Parkinson's disease. Stem Cells. 2008;26(6):1526-1536.

5. Gong S, et al. A gene expression atlas of the central nervous system based on bacterial artificial chromosomes. Nature. 2003;425(6961):917-925.

6. Tomishima MJ, Hadjantonakis AK, Gong S, Studer L. Production of green fluorescent protein transgenic embryonic stem cells using the GENSAT bacterial artificial chromosome library. Stem Cells. 2007;25(1):39-45.

7. Smidt MP, Burbach JP. How to make a mesodiencephalic dopaminergic neuron. Nat Rev Neurosci. 2007;8(1):21-32.

8. Barberi T, et al. Neural subtype specification of fertilization and nuclear transfer embryonic stem cells and application in parkinsonian mice. Nat Biotechnol. 2003;21(10):1200-1207.

9. Placantonakis DG, et al. BAC transgenesis in human embryonic stem cells as a novel tool to define the human neural lineage. Stem Cells. 2009;27(3):521-532.

10. Fasano CA, Dimos JT, Ivanova NB, Lowry N, Lemischka IR, Temple S. shRNA knockdown of Bmi-1 reveals a critical role for $\mathrm{p} 21-\mathrm{Rb}$ pathway in NSC self-renewal during development. Cell Stem Cell. 2007;1(1):87-99.

11. Chalovich EM, Zhu JH, Caltagarone J, Bowser R, $\mathrm{Chu}$ CT. Functional repression of cAMP response element in 6-hydroxydopamine-treated neuronal cells. J Biol Chem. 2006;281(26):17870-17881.

12. Sugita S, Ho A, Sudhof TC. NECABs: a family of neuronal $\mathrm{Ca}(2+)$-binding proteins with an unusual domain structure and a restricted expression pat- tern. NeuroScience. 2002;112(1):51-63.

13. Bolliger MF, Martinelli DC, Sudhof TC. The celladhesion $\mathrm{G}$ protein-coupled receptor BAI3 is a high-affinity receptor for C1q-like proteins. Proc Natl Acad Sci U S A. 2011;108(6):2534-2539.

14. Cui $C$, et al. The beta3 nicotinic receptor subunit: a component of alpha-conotoxin MII-binding nicotinic acetylcholine receptors that modulate dopamine release and related behaviors. J Neurosci. 2003; 23(35):11045-11053.

15. Diez-Roux G, et al. A high-resolution anatomical atlas of the transcriptome in the mouse embryo. PLoS Biol. 2011;9(1):e1000582.

16. Horti AG, Villemagne VL. The quest for Eldorado: development of radioligands for in vivo imaging of nicotinic acetylcholine receptors in human brain. Curr Pharm Des. 2006;12(30):3877-3900.

17. Lindvall O, Kokaia Z. Stem cells in human neurodegenerative disorders--time for clinical translation? J Clin Invest. 2010;120(1):29-40.

18. Bayer SA, Wills KV, Triarhou LC, Ghetti B. Time of neuron origin and gradients of neurogenesis in midbrain dopaminergic neurons in the mouse. Exp Brain Res. 1995;105(2):191-199.

19. Gates MA, Coupe VM, Torres EM, Fricker-Gates RA, Dunnett SB. Spatially and temporally restricted chemoattractive and chemorepulsive cues direct the formation of the nigro-striatal circuit. Eur J Neurosci. 2004;19(4):831-844.

20. Freeman TB, et al. The influence of donor age on the survival of solid and suspension intraparenchymal human embryonic nigral grafts. Cell Transplant. 1995;4(1):141-154

21. Dunnett SB, Bjorklund A. Prospects for new restorative and neuroprotective treatments in Parkinson's disease. Nature. 1999;399(6738 suppl):A32-A39.

22. Nakao N, Frodl EM, Duan WM, Widner H, Brundin P. Lazaroids improve the survival of grafted rat embryonic dopamine neurons. Proc Natl Acad Sci US A. 1994;91(26):12408-12412.

23. Wernig $M$, et al. Neurons derived from reprogrammed fibroblasts functionally integrate into the fetal brain and improve symptoms of rats with Parkinson's disease. Proc Natl Acad Sci U S A. 2008; 105(15):5856-5861.

24. Tesar PJ, et al. New cell lines from mouse epiblast share defining features with human embryonic stem cells. Nature. 2007;448(7150):196-199.

25. Kim JH, et al. Dopamine neurons derived from embryonic stem cells function in an animal model of Parkinson's disease. Nature. 2002;418(6893):50-56.

26. Friling $S$, et al. Efficient production of mesencephalic dopamine neurons by Lmx1a expression in embryonic stem cells. Proc Natl Acad Sci U S A. 2009; 106(18):7613-7618.

27. Shim JW, et al. Enhanced in vitro midbrain dopamine neuron differentiation, dopaminergic function, neurite outgrowth, and 1-methyl-4-phenylpyridium resistance in mouse embryonic stem cells overexpressing Bcl-XL. J Neurosci. 2004;24(4):843-852.

28. Zetterstrom RH, Williams R, Perlmann T, Olson L. Cellular expression of the immediate early transcription factors Nurr1 and NGFI-B suggests a gene regulatory role in several brain regions including the nigrostriatal dopamine system. Brain Res Mol Brain Res. 1996;41(1-2):111-120.

29. Takahashi K, Liu FC, Hirokawa K, Takahashi H. Expression of Foxp4 in the developing and adult rat forebrain. J Neurosci Res. 2008;86(14):3106-3116.

30. Thuret S, Bhatt L, O'Leary DD, Simon HH. Identification and developmental analysis of genes expressed by dopaminergic neurons of the substantia nigra pars compacta. Mol Cell Neurosci. 2004; 25(3):394-405.

31. Mansouri A, Voss AK, Thomas T, Yokota Y, Gruss P. Uncx 4.1 is required for the formation of the pedicles and proximal ribs and acts upstream of Pax9. Development. 2000;127(11):2251-2258.

32. Gong R, et al. Role for the membrane receptor guanylyl cyclase-C in attention deficiency and hyperactive behavior. Science. 2011;333(6049):1642-1646.

33. Panman L, et al. Transcription factor-induced lineage selection of stem-cell-derived neural progenitor cells. Cell Stem Cell. 2011;8(6):663-675.

34. Kriks S, et al. Dopamine neurons derived from human ES cells efficiently engraft in animal models of Parkinson's disease. Nature. 2011; 480(7378):547-551.

35. Schallert T, Fleming SM, Leasure JL, Tillerson JL, Bland ST. CNS plasticity and assessment of forelimb sensorimotor outcome in unilateral rat models of stroke, cortical ablation, parkinsonism and spinal cord injury. Neuropharmacology. 2000; 39(5):777-787. 